\title{
La «confluencia» de los géneros a través del sistema mediático: De la mujer sumisa y el macho ibérico al «ser andrógino» 1
}

\author{
David Hernández Ochoa
}

dherochoa@hotmail.com

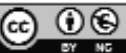

Recibido: 17-05-2007

Aceptado: 16-04-2010

\section{Resumen}

En este artículo, pretende examinarse la evolución de los modelos referenciales que, en torno a los elementos constitutivos de la feminidad y la masculinidad, vendrían siendo masivamente difundidos a través de los medios de comunicación en la sociedad española desde el comienzo de la transición a la democracia. Partiendo de la estricta delimitación en el reflejo mediático de «el hombre» $\mathrm{y}$ «la mujer» que trasciende del franquismo, se analiza el modo en que las representaciones simbólicas predominantes de ambos géneros terminan actualmente convergiendo en un particular paradigma de ser humano, caracterizado por un cierto perfil andrógino.

Palabras clave: género; medios de comunicación de masas; representaciones simbólicas (de la feminidad y la masculinidad); mujer sumisa; macho ibérico; arquetipo andrógino.

Abstract. The «junction» of genders across media system: From the submissive woman and the iberian macho to the "androgynous being"

This article aims to examine the evolution of the referential models which, regarding the constitutive elements of femininity and masculinity, have been circulating on a massive scale through the mass media in Spanish society since the beginning of the Transition. Starting with an exact definition, as reflected by the media, of «man» and "woman» which has come about from the Franco era, the article analyses the way in which predominant symbolic representations of both genders actually end up converging in one particular paradigm if the human being, characterised by a certain androgynous profile.

Key words: gender; mass media; symbolic representations (of feminity and masculinity); submissive woman; iberian macho; androgynous archetype.

1. Pese a que este artículo aborda principalmente la cuestión de la construcción sociocultural de la identidad de género a través de la evolución de los modelos dominantes de la feminidad y la masculinidad, no pretende contribuir al desplazamiento de la problematización académica apuntado por Vendrell (2002) desde el clásico problema de la dominación masculina, que consideramos de auténtica relevancia sociológica, hacia una perspectiva de corte mucho más psicologista centrada en los caracteres identitarios vinculados al hecho de ser hombre o mujer, consecuencia especialmente de la reciente expansión de los men’s sutudies surgidos en Norteamérica. 


\section{Sumario}
1. Introducción
4. A modo de epílogo
2. La evolución de los modelos normativos Referencias bibliográficas heredados del franquismo

3. El advenimiento del «ser andrógino»

\section{Introducción}

Nuestro entorno cultural vendría caracterizándose por la centralidad de un entramado sociocomunicativo articulado en torno a los generalmente conocidos como «medios de comunicación de masas» (MCM), con los que interactuamos asiduamente y de una forma acumulativa y casi automática. De la gran repercusión social de los MCM, y en particular de la televisión ${ }^{2}$, se ha resaltado a menudo el peligro que entraña su enorme potencial para manipular la información mediante la que se refleja (y se construye) la realidad social, aunque cabe también destacar la gran innovación técnica, cultural y estética asociada al desarrollo del fenómeno general de la comunicación de masas.

Dentro de las específicas condiciones de existencia en las que se encuentran, los distintos individuos y grupos sociales pueden poner en práctica un uso activo de los contenidos mediáticos de los que disponen, eligiéndolos y utilizándolos de forma voluntaria y en beneficio de su propio interés personal o colectivo. Desde esta perspectiva, los MCM podrían ser interpretados como una inagotable fuente de información y de experiencias gratificantes, o incluso formando parte de las estrategias de defensa de aquellos agregados de individuos que pudieran padecer discriminación social, lo cual posibilitaría el establecimiento de relaciones afectivas y redes de complicidad en torno a sus producciones, mediante las que algunas personas pueden fomentar su autoestima y reafirmar su identidad. Sin embargo, los distintos contenidos mediáticos pueden también contener determinados mecanismos más o menos conscientes de integración en un orden de estratificación social concreto, como el caracterizado por la supremacía masculina.

En relación con este último aspecto que acaba de comentarse, en un ya clásico estudio de Goffman (1976) sobre la representación de la feminidad en

2. Por la enorme accesibilidad de la que dispone (haciendo acto de presencia en la práctica totalidad de los hogares en la sociedad española), su gran capacidad de seducción y sencilla comunicabilidad (en la que gran cantidad de mensajes visuales y sonoros se dirigen de forma básicamente unidireccional a gran parte de la población, mediante un lenguaje en el que se entremezclan la información con la propaganda y la educación con el entretenimiento), la televisión, actuando en interrelación con los demás MCM, de los que, al mismo tiempo, se perfila como un referente primordial, ha logrado encaramarse en su relativamente corto periodo de existencia como el más relevante instrumento de comunicación social y el principal epicentro cultural de las sociedades avanzadas, tanto, que no se espera que su repercusión sea superada por la de Internet, al menos en un prolongado lapso de tiempo. 
imágenes publicitarias de revistas, este autor observa cómo en los anuncios se dramatiza o se escenifica una imagen ritualizada de la mujer a través de estereotipos sexistas recurrentes, mediante los que se asume de forma manifiesta una interpretación de la realidad femenina parcial, exagerada y distorsionada, de tal modo que establece una clasificación analítica en la que distingue varios tipos ideales de mujeres. La mujer sumisa, la mujer juguete, la mujer dócil, la mujer niña o la mujer oculta serían algunas de las más habituales imágenes femeninas tipificadas que aparecen en los anuncios publicitarios y que tendrían un carácter mucho más simbólico que real, pero, como sostiene Goffman, dicha ritualización femenina estaría en el fondo modelando y reforzando la ritualización «natural» que trata espontáneamente de reproducir cada mujer en su cotidianeidad. De acuerdo con este influyente estudio, podemos ya advertir las profundas implicaciones sociales que se derivan de las representaciones simbólicas sobre el género que mayoritariamente difunden los MCM. En este caso concreto, cómo la imaginería publicitaria femenina puede desempeñar una importante función de control social, actuando como un dispositivo involuntario que induce de forma prácticamente inconsciente a las mujeres a adaptarse a sus representaciones estereotipadas como medio de integración, con la consecuente subordinación a la «mirada masculina» de la realidad que se desprende de estas actitudes «mediáticamente» inducidas.

Tras esta sucinta aproximación a la materia que centrará la presente reflexión, haremos unas breves referencias al trabajo de algunos autores que, dentro del contexto de la sociedad española desde el último cuarto del pasado siglo, han abordado este aspecto de las representaciones simbólicas de los géneros a través de los MCM. Esto nos permitirá adoptar una cierta perspectiva histórica, tratando al mismo tiempo de poner de manifiesto algunas particularidades que, a este respecto, pueden advertirse en nuestro ámbito de estudio. Comenzaremos por abordar la más prolífica cuestión de la iconografía mediática de la feminidad, para después centrarnos en el reflejo que se ha venido ofreciendo en el sistema mediático de la condición masculina. Posteriormente, trataremos de perfilar un novedoso «prototipo de ser humano» que, en los últimos años, parece consolidarse en el discurso público asociado a los MCM, especialmente impulsado desde los contenidos publicitarios, en el que, en cierto sentido, quedarían representadas las personas de todas las condiciones sexuales.

\section{La evolución de los modelos normativos heredados del franquismo}

El citado estudio de Goffman se fundamenta en un trabajo de campo realizado en la sociedad norteamericana entre las décadas de 1960 y 1970 , pero si observamos las imágenes femeninas que predominan actualmente en publicidad, así como en general en buena parte de los contenidos de nuestro entramado mediático, podemos constatar la escasa evolución experimentada por algunas de las más frecuentes expresiones simbólicas del hecho de ser mujer. Más adelante centraremos el análisis en algunas alteraciones en los habituales referentes icónicos y discursos con los que suele presentarse la condición femenina 
en los MCM, aunque quizás resulte conveniente expresar desde aquí nuestra convicción de que la tipología de imágenes femeninas publicitarias propuesta por Goffman en el escenario norteamericano de hace cuarenta años, seguiría teniendo cierta vigencia en nuestro contexto social actual ${ }^{3}$.

Si fijamos concretamente la atención en la sociedad española partiendo del momento en el que Goffman realiza su estudio sobre la ritualización de la feminidad, encontramos un marcado modelo femenino de referencia promovido a través del sistema mediático, que, si bien puede asociarse a algunos de los rasgos arquetípicos observados por el genial autor canadiense, presenta algunas otras características específicas (como un todavía más acusado sometimiento a la autoridad masculina) que guardarían relación con el escenario sociopolítico concreto en el que se manifiesta. Un claro exponente de este modelo de feminidad de los últimos años del franquismo, que en buena medida se hace extensible al periodo de transición a la democracia, es el que se desprende del famoso programa radiofónico Consultorio de Elena Francis, objeto de algunos estudios en el ámbito de las ciencias sociales, entre los que destaca el desarrollado por Imbert (1982) ${ }^{4}$. Este autor muestra como, mediante determinadas estrategias discursivas y figuras retóricas, y a través del marcado universo tópico utilizado en el programa, logra configurarse una muy concisa imagen de «la mujer», que llega a adquirir un fuerte carácter normativo, en la medida en que se constata su importante función como marcador de la identidad femenina de la época, lo cual delimita los marcos de actuación de muchas mujeres.

La representación general de la feminidad que observa Imbert en su análisis del mencionado programa ofrece una visión muy fragmentada de los roles a desempeñar por las mujeres. Dicho análisis obedece a criterios de orden cronológico, social y moral, y básicamente sólo concibe la identidad femenina en relación con la procreación y el vínculo a un espacio familiar ${ }^{5}$. La realidad

3. A este respecto, en un relativamente reciente estudio, algunos autores sostienen que la auténtica condición femenina es invisibilizada a través de los mensajes publicitarios, y es suplantada por una iconografía en la que las mujeres son convertidas en una especie de fantasmas en torno a cualidades que se refieren a la belleza, la perversión o la sumisión (Correa, Guzmán y Aguaded, 2000).

4. El consultorio sentimental femenino de Elena Francis fue transmitido por distintas emisoras dentro del ámbito estatal entre los años 1950 y 1983. Alcanzó destacados éxitos de audiencia, aunque con grandes oscilaciones, y también fue objeto de gran polémica en algunos momentos de sus prolongados años de emisión. El estudio de Imbert sobre el programa al que se hace referencia fue realizado sobre emisiones efectuadas entre los años 1977 y 1980 .

5. Como destacará este autor, en el «universo Elena Francis», las cuestiones relativas al sexo son constantemente idealizadas o confundidas con la maternidad, y el amor y el matrimonio son a menudo representados dentro de la lógica capitalista del ahorro y la rentabilidad. Por otra parte, no puede obviarse el trasfondo comercial y consumista que constituye el fundamento económico de esta producción radiofónica, y que se traduce en un ideal femenino centrado en la estética corporal; el cuerpo pasa a convertirse en un fetiche más de la entonces emergente sociedad de consumo, un objeto de inacabables cuidados intensivos, aunque también de inversión con vistas a su posible rentabilización social. 
femenina queda así claramente delimitada en función a las categorías de puella, uxor o mater familias (o virgen, esposa o matrona), que componen una tipología directamente extraída de la antigüedad clásica. En el programa de Elena Francis, puede hallarse un claro y contundente discurso público basado en un tipo de mujer modélica, en el que la belleza y el sentimentalismo adquieren el carácter de temas de referencia. De ellos, se deriva un modelo de mujer virtuosa y siempre sumisa a la incuestionable autoridad encarnada en la figura masculina del esposo o el padre. El paralelismo de este modelo con las pautas educativas, sociales y culturales del Estado paternalista auspiciado por el régimen franquista resulta, pues, evidente. El programa mostraba una clara intención de orientación de las conductas desde un prisma cargado de tópicos perversos y denigratorios. Aportaba unos mensajes directos y contundentes bajo una cosmología profundamente androcentrista e inspirada en la doctrina católica, sin el menor resquicio para la libertad y la autonomía de las mujeres.

Parece lógico pensar que este modelo anterior de feminidad responde a un pasado en el que, sin duda, la discriminación femenina era mucho más acentuada que en la actualidad; sin embargo, como de algún modo ya se ha apuntado haciendo concretamente referencia a los contenidos publicitarios, las representaciones simbólicas de la feminidad que predominan en el presente panorama mediático, parecen no haber experimentado toda la evolución que cabría esperar en una sociedad que proclama la igualdad formal entre hombres y mujeres ${ }^{6}$. Si nos centramos en la evolución que han experimentado los discursos y las imágenes predominantes en el entramado mediático respecto a la condición femenina hasta sus actuales formas de expresión, hemos de hacer una referencia obligada al brillante análisis cultural de la imagen femenina desarrollado por Gil Calvo (2000), coincidiendo con el momento cronológico del cambio de siglo.

El citado autor elabora una tipología de modelos extremos, que serían el resultado de elevar a su máxima expresión cada uno de los principales atributos sobre los que se estructura la imagen cultural de las mujeres. De esta forma, resultan tres arquetipos de mujer personificados en tres diosas de la mitología griega: Afrodita representa una imagen carnal o fetichista y se correspondería con el arquetipo de «la Puta»; Hera se identifica con una imagen clásica o convencional y encarna la figura de «la Madre», y, por último, la diosa Palas vendría a simbolizar una imagen juvenil o andrógina, característica del modelo femenino de «la Virgen». Gil Calvo defiende que, mediante la existencia de los modelos normativos de «la Madre» y «la Virgen» frente al de «la Puta», se potencia un modo de integración social caracterizado por una obsesión por la

6. En la teórica igualdad entre hombres y mujeres que establece nuestro ordenamiento jurídico, pueden, no obstante, hallarse algunas deficiencias que atestiguan el dominio social y cultural del que aún disfrutan los hombres en nuestra sociedad. En este sentido, el mantenimiento de la línea de sucesión monárquica por descendencia masculina representa un caso paradigmático de discriminación en una sociedad que parece resistirse a abandonar el complejo de supremacía de los hombres. 
imagen de acuerdo con los cánones de legitimidad estética. Por ello, las mujeres tratan de evitar en lo posible la representación de una imagen que, por excesivamente sexualizada, pueda terminar acarreándoles exclusión social. De este modo, la imagen femenina puede ser considerada como un ritual de emancipación, conservación o autodestrucción, mediante el que se expresan las fronteras entre los géneros y los límites sociales que separan a las diferentes clases de mujeres. Como señala el autor, la imagen ritual femenina, adoptada en proporción a la acumulación de otros méritos propios, puede proporcionar placer, autoestima e incluso constituir una fuente de poder en las distintas interacciones sociales; sin embargo, una fijación obsesiva por el ritual femenino de la imagen (en detrimento de la especialización en otros campos que permiten emanciparse con mayor autonomía, madurez y responsabilidad) termina por ser excluyente para gran parte de las mujeres. Por tanto, debe ser desechada.

En el estudio de Gil Calvo, se incidirá en el hecho de que «la imagen femenina» es una construcción social puesta públicamente en escena por la publicidad mediante sus marcados iconos, en general por todos los MCM a través de sus ficciones y sus representaciones de la realidad, y, en última instancia, por mujeres concretas con sus biografías anónimas; aunque, en cualquier caso, la imagen cultural de «la mujer» termina siendo reconstruida por una especie de obsesión fetichista masculina. Por otra parte, creemos conveniente destacar, al hilo de los argumentos de Gil Calvo, la noción de reflexividad. Este concepto hace referencia, en relación con lo que aquí nos ocupa, a que las imágenes con que se representa la realidad también forman parte de la realidad que reflejan. En este sentido, adquiere relevancia el desarrollo de una semántica reflexiva de la imagen femenina que parte de la consideración de que las oportunidades vitales de los distintos sujetos (en este caso, las mujeres) pueden ser modificadas en función de cómo se defina la imagen que de ellos se ofrece públicamente.

Otro reseñable aspecto apuntado por este último autor para lo que aquí respecta, es el que se refiere a la predominante confluencia de las representaciones simbólicas de la feminidad en un modelo común aparentemente superador del excluyente arquetipo de la sumisión, que representaría tanto a jóvenes solteras como a adultas casadas. Se confirma, en definitiva, el creciente predominio de un determinado ideal de mujer moderna y «liberada» (como el que frecuentemente se desprende del reflejo mediático de la realidad), pero en el que, no obstante, continúan pudiendo vislumbrarse ciertos efectos discriminatorios sobre las condiciones de vida femeninas. El autor hace concretamente referencia a un novedoso arquetipo de virgen madre, que se corresponde con el que tratarían de encarnar las top models. Un modelo construido a partir de figuras de referencia y contrarreferencia que prescribe una imagen femenina juvenil y lo más atractiva posible, con lo cual se erige como imagen canónica de la única edad concebible de la mujer (Gil Calvo, 2000: 289).

Centrándonos ahora en la evolución que han experimentado las representaciones simbólicas predominantes de la masculinidad, partiendo concre- 
tamente de nuevo de los últimos años del programa de Elena Francis (referente del discurso hegemónico sobre los géneros en los primeros años de la transición a la democracia, con marcadas reminiscencias ideológicas del régimen sociopolítico anterior), Imbert nos ofrece una clasificación analítica de los prototipos de hombre que suelen aparecer en el programa, en relación con los roles y las funciones considerados a desempeñar por el género masculino en la sociedad. De esta forma, la figura masculina es representada como «responsable» o "que no da la talla», pero, en cualquier caso, en continua remisión a su categoría de principal instancia social y familiar. Los hombres pueden adoptar el rol de novio, padre o esposo, pero siempre se les asigna una función representativa respecto a la mujer; por lo demás, la imagen masculina que se refleja queda un tanto desdibujada: el hombre aparece como un ser misterioso, a menudo distante, situado a medio camino entre la divinidad y una naturaleza salvaje. Este modelo de masculinidad también se caracteriza por el carácter rústico y elemental en el plano afectivo y sentimental, de tal forma que una supuesta igualdad entre los sexos en lo que concierne a la expresión de los sentimientos se perfila como intolerable, de modo que cualquier hombre que se muestre notoriamente influenciado por sus emociones afectivas es tachado de sensiblero (el insensible e impulsivo macho ibérico se resiste a desaparecer como modelo de referencia para los hombres y todavía tendrá tiempo de ser rescatado o reconstruido desde algunos discursos mediáticos o políticos).

No debemos olvidar el papel principal de los MCM como «marcadores de identidad" y, en definitiva, como "productores de realidad", un aspecto que es también destacado en el trabajo de Imbert, para quien, de igual forma que la prensa, puede construir un acontecimiento, la publicidad puede crear o reforzar modelos, y el cine y la televisión pueden difundir y divulgar temas, definir identidades, y hacer «existir» realidades sociológicas (Imbert, 1990: 98). Este autor considera de especial relevancia la función desempeñada por el cine en la transición, puesto que dicho medio constituyó un reflejo más o menos mediatizado de una formación social, de un imaginario colectivo, de cierto tipo de narración y, en definitiva, de un sistema significante. Para Imbert, la producción cinematográfica durante la transición se caracteriza por la escenificación del lenguaje y por ser un cine de representación, es decir, por su signo realista en la delimitación y caracterización de un periodo histórico distinguido por profundos cambios económicos, políticos, sociales y culturales. En lo que concierne a la representación de la masculinidad, el autor destaca una cierta crisis en la identidad colectiva de los hombres, que, en buena medida, se traduce en el dilema (ficticio o real) de asumir una identidad machista o no machista. En este sentido, en algunas películas, aparece lo que denomina «el macho de síntesis» (Imbert, 1990: 109), un hombre a medio camino entre el «bruto de puños de acero» y el «romántico de corazón tierno», cuyo referente cultural procedería en cierta medida del prototipo de macho ibérico característico del franquismo. El retrato general masculino que muestra este cine pasa por un hombre que no se muestra machista en su comportamiento cotidiano, aun- 
que puede preservar ciertas actitudes que, en la actualidad, podrían ser calificadas de sexistas; un hombre no excesivamente paternalista a pesar de sus cualidades como protector, que puede ser infantil en su relación con las mujeres, pero "macho» en lo que respecta al espacio público, y puede llegar a adoptar comportamientos inflexibles y violentos.

Para tratar de complementar, y en la medida de lo posible contrastar este modelo mediático de masculinidad de la transición descrito por Imbert, nos detendremos brevemente en un interesante estudio llevado a cabo por Grau Rebollo (2002), en el que examina la percepción social de los modelos normativos referentes a la familia y al parentesco (concretamente, de las clases medias urbanas), que nos llegan a través de los medios audiovisuales, especialmente largometrajes comerciales, teleseries de ficción y reportajes televisivos. Este autor muestra un especial interés por el análisis de productos mediáticos comerciales a causa de su gran repercusión social, y sostiene que los modelos culturales de estos productos coinciden con los de la vida cotidiana, ya que, al igual que en ésta, las «conductas desviadas» vendrían a legitimar y fortalecer el «comportamiento adecuado». Por otra parte, la voluntad didáctica de estos documentos, dentro de la lógica de lo "políticamente correcto", hace que comúnmente incurran en una cierta transmisión ideológica.

Grau Rebollo coincidirá con Imbert en destacar la supervivencia del estereotipo de la virilidad ibérica (en este caso concreto, mediante el análisis de la producción cinematográfica en nuestro contexto entre los años 1971 y 1982), que tendrá una curiosa reencarnación simbólica en la esfera sociopolítica en la figura de Tejero, y que, en el caso del cine, adquiere ciertas connotaciones humorísticas en el subgénero de películas conocidas como «españoladas» o "de destape», a través de varios actores que representan de modo continuado este último reducto del «auténtico macho ibérico», que ya comienza a mostrarse ridículo y desfasado. Para el autor, estos «subproductos» del cine español se caracterizan por la búsqueda de una rápida rentabilidad, y en ellos se pone claramente de manifiesto el carácter androcéntrico de la sociedad en lo que respecta a la representación de la misma y al consumo de estos productos mediáticos, en los que la mujer comienza a ser sexualizada como objeto de deseo. Sin embargo, al mismo tiempo, se produce un cierto resquebrajamiento del modelo normativo de mujer característico del régimen franquista (la mujer sumisa), a través de las representaciones de «la extranjera» y «la joven».

Como también pondrá de manifiesto Gil Calvo en otra de sus destacadas obras (1997), la necesidad del doble ingreso que irá imponiéndose en la modernidad tardía, en muchos casos como único medio para soportar el peso de la carga familiar, repercute indudablemente en una minimización del tradicional sindrome de supremacía masculina (tan claramente expresado a través del sistema mediático): el «derecho» de los hombres a ser machistas y hacerse respetar, que emanaba de su incuestionable rol de cabeza de familia en la sociedad moderna (la obligación institucional de "ganarse la vida» de uno mismo y la de «los suyos»). Sin embargo, la destrucción del complejo de superioridad rela- 
tiva que experimenta el varón postmoderno termina por ser sólo cuantitativa y gradual, ya que, como es bien conocido, no ha llegado a alcanzarse una igualdad social de facto entre los dos géneros.

\section{El advenimiento del «ser andrógino» ${ }^{7}$}

Pese al evidente mantenimiento de la segregación social entre géneros que queda plasmada en el sistema mediático, consideramos que, desde los últimos años del pasado siglo, se vendría produciendo una relativa aproximación entre las tradicionales representaciones simbólicas del hecho de ser hombre o mujer, que terminan por converger en lo que podría, en cierto sentido, abstraerse como un novedoso "patrón de individuo" (mitificado en ocasiones desde los MCM como paradigma del ser humano para el futuro), en el que quedarían de algún modo proyectados tanto hombres como mujeres, y que, por tanto, presenta, entre sus rasgos más destacados, una aparente «asexualidad». El nuevo mito mediático que, en ocasiones, pareciera profetizar una futura sociedad habitada por individuos «culturalmente andróginos», suele ser inherente al quizás más conocido y casi incuestionado discurso que ensalza las bondades de la sociedad de consumo, de las nuevas tecnologías y del prometedor futuro que han de depararnos, lo cual nos ofrece a menudo la utopía de un cada vez más próximo mundo entre iguales por razón de sexo.

Aunque su origen sea muy probablemente anterior, el mito del andrógino se encuentra ya contenido en la obra de Platón, donde es utilizado alegóricamente para tratar de explicar la génesis de la humanidad como un estado de perfección originario del actual e imperfecto ser humano dividido en sexos. Se trata de un mito de carácter universal, que será también recuperado por influyentes autores en el ámbito de las ciencias sociales, como es el caso de Sigmund Freud, quien se vale del clásico mito platónico para tratar de justificar simbólicamente la pulsión sexual como el intento por recuperar un edénico estado prenatal previo a la diferenciación genital, en el que el sujeto carece de conflictos.

Por lo que aquí se refiere, pensamos que, en la actualidad, se estaría consolidando una novedosa y peculiar versión del mito del andrógino, que cobra forma a partir de gran parte de los contenidos difundidos a través del sistema mediático, como resultado de una marcada tendencia a la representación simbólica de las personas en base a un determinado arquetipo que presenta una cierta ambigüedad en lo relativo a su caracterización sexual (al menos en comparación con el pasado). Un «nuevo ser» especialmente promovido desde algunos de los mensajes publicitarios que sobreabundan en los MCM, que tendría como uno de sus rasgos más destacados el culto a la imagen corporal, y que se expresa con claridad en el creciente predominio mediático de «cuerpos» (tanto

7. El término procede de los conceptos de la Grecia antigua andros ('hombre') y ginos ('mujer'), y designa a un ser que carece de diferenciación sexual, que es masculino y femenino a la vez. 
de hombres como de mujeres) caracterizados por su esbeltez y juventud, al margen de su delimitación sexual. Unos cuerpos que, en múltiples ocasiones, se muestran aparentemente desexualizados, en cierta medida "deshumanizados» y convertidos en simples objetos por sus cualidades estéticas.

La relativa imposición de un tipo ideal andrógino como nuevo canon cultural (un referente figurativo en cuya configuración e implantación social los MCM en general, la televisión, y la publicidad que en buena medida los sustenta, desempeñan un papel primordial) no sería tanto el resultado de una deliberada y desinteresada óptica sociocomunicativa en pos de una auténtica «justicia intergenérica», como a priori pudiera pensarse, sino más bien consecuencia de una extendida voluntad por promocionar valores específicos que entrañan una cierta exaltación y encubrimiento de algunos aspectos de la realidad y, por tanto, la transmisión de ideología ${ }^{8}$. Sin embargo, resulta bastante frecuente encontrar, en los contenidos televisivos de la actualidad, a personas o a personajes que desempeñan roles o que muestran actitudes anteriormente asignados al género contrario, de tal forma que no resulta extraño el hecho de que aparezcan hombres convertidos en objetos sexuales o estéticos, o mujeres revestidas de una gran autoridad sobre los hombres, lo que, unido a la proliferación de un perfil relativamente desexualizado, contribuye de algún modo a la consolidación de una cierta «imagen unisex».

Las imágenes y los discursos con los que simbólicamente se representan determinados aspectos de la realidad guardan, lógicamente, una estrecha relación con el contexto social concreto en el que tienen lugar. En este sentido, el nuevo arquetipo andrógino no constituye ninguna excepción. De acuerdo con esta premisa, un factor determinante en el afianzamiento de esta novedosa «imagen asexuada» lo constituye la relativa igualación social entre hombres y mujeres acontecida durante las últimas décadas. Elias muestra como la primera convergencia histórica entre géneros tuvo lugar en las cortes monárquicas europeas de la modernidad temprana, donde las mujeres comienzan a competir con los hombres por hacerse un hueco entre las élites sociales e intelectuales que se congregaban en estas cortes ${ }^{9}$. De modo análogo a este proceso, la consolidación de un prototipo de ser andrógino durante la segunda mitad del siglo XX debe enmarcarse en un contexto en el que muchas mujeres renuncian

8. De este modo, la proliferación mediática de personas con un cierto perfil andrógino podría quizás interpretarse más en relación con la puesta en práctica de una generalizada estrategia comercial, que con la difusión de un discurso social verdaderamente proclive a la equiparación social entre hombres y mujeres. A este respecto, puede fácilmente constatarse que la «androginia mediática» coexiste con otros fenómenos sociocomunicativos en buena medida contrapuestos a una aproximación real entre géneros, como la habitual erotización de la imagen femenina o la naturalización de actitudes y, por tanto, funciones a desempeñar en la sociedad por cada uno de los sexos de nacimiento.

9. El autor analiza cómo, dentro de estos grupos aristocráticos, comienza a producirse un refinamiento de la imagen de las mujeres y un cierto «afeminamiento» en la de los hombres, al tiempo que ambos géneros comienzan a adoptar rituales andróginos de presentación en sociedad (Elias, 1989). 
a la exclusividad de su asignación al ámbito doméstico, para pasar a competir con los hombres en todos los ámbitos de la esfera pública.

Una aproximación teórica al modo en que un relativo perfil andrógino logra consolidarse como un nuevo referente identitario para ambos géneros, podría desarrollarse partiendo del análisis de un fenómeno social como la moda ${ }^{10}$. La corriente principal de la sociología de la moda parte de la teoría clásica de Simmel, para quien el fenómeno consiste básicamente en un continuo proceso de innovación y emulación a través del cual se expresa y se canaliza la competencia entre los distintos estratos sociales (Lozano, 2000). Esta corriente principal estaría más recientemente representada por autores como Bourdieu (1988) o Baudrillard (1999), de los que se desprende que la moda constituye un mecanismo mediante el cual se manifiesta la competencia vertical entre las clases, un instrumento que posibilita la diferenciación y el distanciamiento entre grupos sociales e incluso la movilidad ascendente en el seno de la estructura social moderna. Por su parte, para otro influyente teórico de la moda como es Lipovetsky (1990), el fenómeno se encontraría principalmente asociado con la interacción entre personas o grupos situados en el mismo nivel de la estructura social, actuando como un dispositivo capaz de inducir y consolidar relaciones sociales de tipo horizontal (ya sean de competencia o solidaridad) y posibilitando el establecimiento de vínculos comunicativos de naturaleza emocional. En este sentido, siguiendo a Lipovetsky, al fenómeno de la moda le es inherente una importante función expresiva que se concentra especialmente en las relaciones sociales de seducción y, de manera prioritaria, en la tensión sexual y amorosa que tiene lugar entre los géneros, hasta el punto de llegar a considerar las relaciones de seducción entre sexos como la principal fuerza propulsora del sistema de la moda (que tanto hombres como mujeres utilizarían no tanto para diferenciarse del sexo contrario, como para ser positivamente distinguidos por el mismo). Desde otra perspectiva, Blumer (1977) considera el proceso de la moda como un auténtico regulador del cambio social; un mecanismo capaz de propiciar, de manera prácticamente involuntaria e incluso inconsciente, nuevas actitudes y pautas de comportamiento que pueden llevar aparejada cierta funcionalidad en un entorno sociocultural en continua evolución. Cerraremos este necesariamente breve recorrido teórico por el fenómeno de la moda aludiendo a otra destacada autora como Entwistle (2002), quien, recientemente, ha destacado el papel esencial que la moda desempeña en la configuración de la identidad contemporánea, median-

10. Las siguientes consideraciones sobre la moda se basan fundamentalmente en la aportación que, para el estudio del fenómeno, realiza Gil Calvo, quien, de acuerdo con la corriente principal de la sociología de la moda, considera a ésta como la "[...] modificación periódicamente cíclica de los principales signos externos del comportamiento personal en público: vestimenta, presencia física, usos sociales, reglas de etiqueta, diseño de útiles cotidianos, estilo estético e intelectual, etc., etc., con fenómenos adicionales de resonancia en eco, por los que muchas formas impersonalmente estructuradas, como el arte, la ciencia, el pensamiento o la arquitectura, resultan igualmente sometidas en cierta medida al trabajo del proceso de la moda» (Gil Calvo, 1991: 31). 
te la confluencia del cuerpo, el género y la sexualidad que acontece en la sociedad actual.

Las distintas perspectivas analíticas que acaban de esbozarse podrían ser adoptadas complementariamente para tratar de explicar la proliferación de un prototipo de ser humano andrógino como una nueva moda especialmente fomentada desde los MCM. De esta forma, de acuerdo con la corriente principal de la sociología de la moda, puede pensarse que la adopción de un cierto perfil andrógino (tanto por hombres como por mujeres) respondería a un novedoso signo de distinción de los grupos sociales acomodados e incluso a una deliberada estrategia personal para tratar de ascender en la estructura social. Del mismo modo, en base al razonamiento de Lipovetsky, podría argumentarse que la androginia constituye una nueva moda utilizada por ambos géneros en las relaciones de seducción, para tratar de diferenciarse positivamente de las personas de su mismo sexo respecto al sexo contrario. Por último, en la línea del pensamiento de Blumer o Entwistle, el novedoso y compartido modelo de ser humano andrógino puede vislumbrarse como un elemento de cada vez mayor relevancia en la configuración de la identidad contemporánea, en un escenario como el actual en el que tienden a reducirse las diferencias socioculturales entre los géneros, lo cual exige adoptar, aunque sea inconscientemente, actitudes y conductas más adaptativas a los nuevos tiempos.

El actual arquetipo andrógino comienza a perfilarse por un acercamiento de la imaginería femenina a la masculina, lo cual parece razonable si se considera que las mujeres comienzan a demandar el mismo grado de libertad del que disfrutan los hombres, para lo cual recurren frecuentemente a rituales y a comportamientos emancipatorios, que hasta hace relativamente poco tiempo eran de un casi absoluto monopolio masculino. La acentuada liberación femenina que tiene lugar en nuestro contexto desde la década de los setenta incide en el hecho de que muchas mujeres abandonen los tradicionales y discriminatorios arquetipos del sentimentalismo y la sumisión, y las nuevas generaciones de mujeres, al igual que los hombres, ponen en práctica signos andróginos de liberación que toman forma en la adopción de una estética corporal muy similar, una vestimenta parecida, así como unas actitudes, unos gestos, una posturas y unos ritos transgresores compartidos, todo lo cual puede observarse con claridad en los múltiples contenidos difundidos a través del sistema mediático.

Pero en la confluencia de los géneros en el arquetipo que estamos definiendo como «ser andrógino", no sólo acabaron por imponerse aquellos rasgos o atributos que hasta entonces más habían caracterizado a los hombres, sino que éstos también terminan por asumir ciertas pautas de comportamiento y elementos identitarios que hace tan sólo unos años hubieran sido colectivamente considerados como anormales para ellos, lo cual les habría acarreado el estigma de «afeminados». Ya no es inusual que los hombres dediquen costosos recursos al tradicionalmente más femenino ritual de la imagen (y no nos referimos solamente a algunos hombres que ya llevan tiempo prestando una especial dedicación a este aspecto, como es el caso de un alto porcentaje de los individuos perteneciente al colectivo gay); el antiguo perfil de «hombre duro» (en 
nuestro caso, «macho ibérico») es progresivamente suplantado como modelo referencial por un hombre sensible, comprensivo y capaz de mostrar sus debilidades, lo cual supone una cierta reorganización de las relaciones en el seno familiar. Las compañeras son quizás más tomadas en consideración en lo que respecta a cuestiones afectivas o sexuales, comienza a prestarse una mayor atención al cuidado de los hijos en lo que podría considerarse una nueva dimensión de la paternidad caracterizada por una mayor implicación emotiva, algunos hombres deciden también renunciar a una carrera profesional «a tiempo completo» en beneficio del cuidado de la familia o el mantenimiento del hogar; fenómenos todos ellos que expresan con claridad la puesta en práctica de nuevas masculinidades (Carabí y Segarra, 2000), en cierto modo, superadoras de la histórica escisión entre razón y emoción vinculada a la identidad masculina (Seidler, 2000). Sin embargo, pese a la relativa aproximación entre los rasgos constitutivos de las tradicionales identidades femenina y masculina, muchos hombres consideran compatible la «igualdad entre géneros» y el mantenimiento de la antigua división del trabajo, al tiempo que los cambios que acaban de comentarse constituyen un buen pretexto para el desarrollo de una cierta retórica de la igualdad entre los hombres y entre las propias mujeres (Beck y BeckGernsheim, 2001).

La exaltación mediática del arquetipo andrógino puede interpretarse mejor dentro de una lógica comercial, como una determinada estrategia de marketing, que como un discurso racional que propugna una auténtica igualdad social entre los géneros. En este sentido, no es casual el hecho de que la publicidad se perfile como un resorte fundamental en la implantación de este nuevo modelo. Dentro del universo publicitario, que en buena medida es el contenido que dota de una cierta coherencia al aparentemente inconexo conjunto de contenidos mediáticos, las representaciones de las personas pueden adquirir múltiples formas. Sin embargo, como se viene señalando, se está tendiendo cada vez más a la utilización de una imagen basada en la corporalidad, en cierta medida desexualizada y que adquiere valor como un elemento estético que puede ser empleado como estrategia para vender cualquier cosa. Si el cuerpo es la base de nuestra identidad, el sustento de nuestra existencia, también se convierte en un referente fundamental dentro del universo icónico de nuestra sociedad. Como parte integral de la sociedad de consumo, los MCM se convierten en los principales promotores de unos cuerpos jóvenes, delgados y «perfectos», como los que constantemente aparecen en su reflejo de la realidad. Los cuerpos femenino y masculino se equiparan en cierto modo en cuanto al uso que se hace de ellos por los MCM de acuerdo con el imperativo estético señalado; pero, al mismo tiempo, el cuerpo se convierte en una fuerza productiva que puede ser rentabilizada al máximo como instrumento de consumo. Los cuerpos, indistintamente del sexo al que pertenezcan, son expuestos y consumidos como una mercancía más, y, como primordial instancia de consumo en nuestra sociedad, se constituyen en el principal objetivo de importantes empresas comerciales como las relativas a la cosmética, la moda, la cirugía estética, la alimentación o el deporte. 
La sociedad consumista y «mediatizada» en la que nos encontramos se organiza sobre una estructura económica caracterizada por una enorme competitividad, y lo hace en base a determinados valores como aquéllos que ensalzan el culto a un cuerpo sano, atlético, joven y bello. La demanda del carácter competitivo como medio de integración social se relaciona con el desarrollo de prácticas más o menos recreativas y gratificantes que fomentarán dicho carácter competitivo. Un claro ejemplo de este aspecto es el que se observa en la enorme repercusión social que ha ido adquiriendo el deporte (como práctica y como espectáculo), de modo que constituye el símbolo por excelencia de la competitividad (aunque también una clara muestra y un enaltecimiento de la potencia física masculina superior). La creciente rivalidad entre hombres y mujeres en el ámbito público ha llevado a estas últimas a desarrollar pensamientos, actitudes y conductas que fomentan el valor de la competencia. En ese sentido, podría en parte interpretarse la creciente incidencia que la cultura deportiva va adquiriendo entre el género femenino. Muchas mujeres encuentran además en el deporte un importante medio que les abre la posibilidad de acercarse, aunque sea levemente, al modelo corporal que encarna «la perfección». Por su parte, el imperativo estético es también asumido ahora en mayor medida por los hombres como estrategia competitiva, en el marco de una cultura caracterizada por una relativa obsesión por la imagen y las apariencias. Además, los productos dirigidos al consumo masculino comienzan a tener una creciente importancia dentro de las todavía predominantemente femeninas industrias de la moda, la cosmética o la cirugía estética.

Como consecuencia de todos estos procesos que se vienen describiendo, va tomando forma el arquetipo referencial andrógino, que engloba a hombres y a mujeres en una imagen parecida y en unas pautas de actuación comunes, en las que se incluyen caracteres anteriormente no atribuidos socialmente al sexo de pertenencia. Por otra parte, en estos procesos, puede observarse el cierre de un ciclo que responde a la perfección a la lógica capitalista de crear nuevos ámbitos de mercado o de amplificarlos al mayor número posible de consumidores: mientras que las mujeres comienzan a utilizar productos anteriormente masculinos (como los relativos a ritos emancipatorios o a la actividad deportiva), aquellos otros que, en buena medida, configuraron a las mujeres como un colectivo con entidad propia en la sociedad de consumo (productos sobre todo destinados al cuidado de la imagen), se abren ahora al nuevo e inmenso potencial mercado masculino, que pasa a convertirse en un importante objetivo para importantes industrias comerciales por su gran volumen y poder adquisitivo.

No podemos concluir esta breve reflexión sobre lo que puede considerarse una versión actualizada e ideologizada del mito del andrógino, sin señalar un importante fenómeno sociocomunicativo que constituye una parte sustancial en la configuración, la difusión y la influencia del nuevo arquetipo. Nos referimos al hecho de que, sobre todo en las dos últimas décadas, han irrumpido en el espacio público determinados colectivos o personas cuya identidad de género u orientación sexual cuestiona rotundamente la tradicional diferencia- 
ción social entre los sexos. La visibilidad social de gays, lesbianas, bisexuales, travestis o transexuales (colectivos cuyo análisis suele englobarse bajo el genérico queer studies) ha provocado una cierta ambigüedad respecto a la concisa división social por géneros heredada del régimen franquista (donde el sexo de nacimiento determinaba el género y la orientación sexual de las personas, al menos públicamente), lo cual ha contribuido también, en cierto sentido, a conformar el ideal de un ser andrógino, que se perfila como un nuevo arquetipo social en el que parecen de algún modo poder verse simbolizadas todas las personas, al margen de su condición sexual ${ }^{11}$.

En definitiva, retomando el hilo de nuestra argumentación principal, si a la comentada confluencia entre algunos de los rasgos con los que se representa simbólicamente la masculinidad y la feminidad, añadimos la creciente visibilidad pública fomentada por los MCM de personas cuya identidad de género, orientación sexual, estética corporal o modo de actuar o de expresarse no guardan aparente relación con los atributos sexuales de nacimiento, tenemos como resultado un prototipo mediático de ser humano en cierto modo asexual, andrógino, aunque, en cualquier caso, siempre fiel a los principios de una nueva ética que prescribe el culto a la imagen corporal (preceptos éticos que implican el consumo de un sinfín de productos).

\section{A modo de epílogo}

El arquetipo mediático andrógino que acaba de esbozarse, lejos de sustentarse en un discurso reflexivo y fundamentado en la deliberación y el consenso de la ciudadanía, se restringe más bien al influjo sociocomunicativo de determinados caracteres en los que confluye la representación simbólica de las personas de ambos sexos, con un evidente trasfondo consumista. El ideal andrógino es, en buena medida, un modelo referencial impuesto "desde arriba", perfilado y promulgado fundamentalmente desde diversas agencias publicitarias a través de los MCM, y cuya implantación social resulta muy rentable para el mercado, lo cual beneficia a un buen número de industrias. Se trata de un

11. La gran profusión de historias personales de revelación de la homosexualidad o transexualidad por televisión y, por otros medios, tanto de seres anónimos como de personas de reconocido prestigio, adquiere una considerable importancia en el proceso de aceptación social y construcción de una nueva identidad para otras muchas personas. De esta forma, el contacto mediático con historias personales similares puede ser un importante punto de referencia a la hora de establecer un lenguaje que dote de sentido a la experiencia personal, un imaginario común que proporcione el sentimiento de pertenencia a un colectivo específico y una identidad social coherente que provea de cierto apoyo emocional. Sin embargo, como en tantos otros aspectos, también en éste pueden hallarse notables discordancias entre los géneros, de tal modo que la actualmente considerable visibilidad pública de la homosexualidad masculina contrasta con la menos conocida, representada y difundida realidad de las mujeres lesbianas (en lo que puede considerarse una clara manifestación de la discriminación social y mediática de las mujeres), quienes, por otra parte, tendrían más reservas en revelar su identidad sexual, quizás por un mayor temor que los hombres respecto a ser víctimas de una discriminación social más acentuada (Viñuales, 2000). 
ser humano ejemplar dotado de «sensibilidad femenina» y «competitividad masculina", enormemente funcional para el sistema socioeconómico y que se circunscribe a la "corrección política» propugnada por los MCM (en relación con la discriminación femenina), en la medida en que su sanción pública a través de todo el entramado mediático, y especialmente la publicidad, puede ser entendida como la incorporación del «lado femenino» en lo que se difunde como un nuevo prototipo de ser humano; un ideal de individuo que podría comprenderse como una versión adaptada del pretérito mito del andrógino, porque de algún modo preconiza un "particular estado de perfección» de la humanidad, superador de las tradicionales asignaciones socialmente atribuidas a cada sexo de nacimiento ${ }^{12}$. Sin embargo, como resulta evidente, el «nuevo ser andrógino" suele presentar perfiles en gran medida contrapuestos y, en términos generales, coincidentes con el género de los sujetos (reales o ficticios) que lo personifican.

Centrándonos de nuevo en la irrupción en los MCM de los colectivos que han cuestionado la tradicional continuidad entre el sexo de nacimiento, la identidad de género y la orientación sexual, podemos advertir cómo, en determinados casos, algunas de las personas pertenecientes a estos colectivos logran escenificar una imagen estética y un perfil psicológico que bien pudiera pensarse que responde a la perfección al ideal del ser andrógino (por lo que resulta en ocasiones de enorme dificultad determinar el sexo al que pertenecen algunas de estas personas que, con relativa asiduidad, hacen acto de presencia en el medio televisivo). Sin embargo, quizás sea más frecuente encontrar, en el reflejo mediático de estos colectivos, una sobrerrepresentación de algunos individuos con caracteres personales o atributos corporales que suponen una exageración, cuando no llevar al extremo los rasgos definitorios de los modelos tradicionales de masculinidad y feminidad, aunque sea partiendo de una trasgresión de la base de estos modelos (como es la ruptura de la relación directa entre el sexo, el género y la orientación sexual). Por otra parte, la representación de estos colectivos suele ofrecernos una realidad muy simplificada y en la que muchas veces no se ven reflejados. La común recurrencia mediática a la utilización de estereotipos o prejuicios con evidentes connotaciones negativas hace que estos colectivos puedan ser utilizados como contrarreferencia de los modelos «normales» del hecho de ser hombre o mujer.

En lo que concierne a las representaciones actualmente predominantes del conjunto de los hombres y mujeres, como se ha comentado, la irrupción femenina en el ámbito público ha promovido una simbología y unos elementos identitarios en cierta medida unisex, al tiempo que hombres y mujeres pasan a compartir protagonismo en los contenidos del entramado mediático. Como

12. En este último sentido, el arquetipo andrógino estaría en cierta medida alimentando un discurso ideológico que parecería celebrar la igualdad social entre los géneros como «algo hecho", ya que, como se muestra a través de los MCM, hombres y mujeres compartirían protagonismo en la esfera pública, además de una serie de rasgos estéticos y de personalidad. 
también se ha dicho, las nuevas representaciones simbólicas del género coinciden en la unicidad del consumo de productos relativos al cuidado del cuerpo y de la imagen estética, sin embargo, en el mercado, encontramos una clara dualidad en la oferta de estos productos en relación con el género de sus consumidores, que continúa delimitando, legitimando y fomentando el fenómeno diferencial (biológico y social) de pertenecer a uno u otro género. Por su parte, el supuesto protagonismo compartido de los géneros en el reflejo mediático de la realidad, consecuencia de la progresiva liberación femenina, merecería ser cuestionado si se analiza con un poco de atención en qué medida y de qué forma son representados hombres y mujeres y las relaciones entre ambos (de modo que se pueda percibir en buena parte de los contenidos mediáticos un pronunciado ensalzamiento de la masculinidad, que, a veces, pasa por una informal aunque innegable denigración de «lo femenino») ${ }^{13}$.

Pese a la cada vez más recurrente "androginia mediática» que aquí ha tratado de perfilarse, consideramos que ésta puede desglosarse fácilmente en dos modelos referenciales específicos de la feminidad y la masculinidad, que podrían extraerse en términos generales del conjunto de las nuevas producciones mediáticas que son masivamente difundidas en nuestro contexto de estudio. Aunque, en esta ocasión, no tenemos oportunidad de desarrollar este razonamiento, queremos al menos dejar constancia de la destacable insistencia mediática en un particular modelo de mujer de hoy, que, pese a su proclamado perfil postmoderno y a la incuestionable emancipación femenina que le es inherente, tendría mucho más en común con la «mujer de ayer», en nuestro caso representada por el modelo de feminidad implícito al comentado programa radiofónico de Elena Francis, de lo que a primera vista pudiera parecer; y, por lo que se refiere a la imaginería masculina, puede constatarse el cada vez mayor predominio en los MCM de un modelo todavía emergente en lo relativo a su impacto social, aunque profusamente utilizado en las múltiples producciones destinadas a la difusión mediática (y especialmente enaltecido desde algunos contenidos publicitarios), que se corresponde con ese «nuevo hombre» comúnmente conocido bajo el apelativo de metrosexual, que, aparentemente, implica una gran evolución de la imagen cultural masculina (al ser un modelo en buena medida antagónico al tradicional paradigma de la virilidad ibérica). Dos modelos referenciales de las actuales condiciones femenina y masculina, que, pese al impulso hacia la paridad social entre géneros que, en principio, pareciera derivarse de su compartido perfil «andrógino», consideramos que, por el contrario, seguirían incidiendo de modo informal (aunque certero) en el mantenimiento en términos generales de una cierta distancia social entre el común de los hombres y de las mujeres.

13. Para una certera aproximación a los desajustes respecto a la realidad que tienen lugar en el reflejo mediático de la feminidad y la masculinidad, puede consultarse la publicación Medios de comunicación, mujeres y cambio cultural (Muñoz, 2001). 


\section{Referencias bibliográficas}

Baudrillard, J. (1999). Critica de la economía politica del signo. México: Siglo XXI. BeAsley, Ch. (2005). Gender and Sexuality: Critical Theories, Critical Thinkers. Londres: Sage Publications.

BECK, U. y BECK-GERNSHEIM, E. (2001). El normal caos del amor: Las nuevas formas de la relación amorosa. Barcelona: Paidós/El Roure.

BERnÁRDEZ, A. Cuerpos imaginarios: ¿exhibición o encubrimiento de las mujeres en la publicidad?. [http://www.ucm.es/info/per3/cic/cic5ar5.htm, consulta: febrero de 2006]

Blumer, H. (1977). «Moda». En: Sils, D.L. Enciclopedia Internacional de las Ciencias Sociales. Madrid: Aguilar, 155-157.

Bourdieu, P. (1988). La distinción: Criterios y bases sociales del gusto. Madrid: Taurus.

- (2000). La dominación masculina. Barcelona: Anagrama.

Carabí, A. y Segarra, M. (eds.) (2000). Nuevas masculinidades. Barcelona: Icaria.

CorreA, R.I.; GuZMán, M.D. y AGUADED, J.I. (2000). La mujer invisible: Una lectura disidente de los mensajes publicitarios. Huelva: Grupo Comunicar.

Elias, N. (1989). El proceso de la civilización. México D.F.: Fondo de Cultura Económica.

ENTWISTLE, J. (2002). El cuerpo y la moda: Una visión sociológica. Barcelona: Paidós.

ERIBON, D. (2001). Reflexiones sobre la cuestión gay. Barcelona: Anagrama.

Gil Calvo, E. (1991). La mujer cuarteada: Útero, deseo y safo. Barcelona: Anagrama.

- (1997). El nuevo sexo débil: Los dilemas del varón posmoderno. Madrid: Ediciones Temas de Hoy.

- (2000). Medias miradas: Un análisis cultural de la imagen femenina. Barcelona: Anagrama.

GOFFMAN, E. (1976). «La ritualización de la feminidad». En: GofFMAN, E. (1991). Los momentos y sus hombres. Barcelona: Paidós, 135-168.

Grau Rebollo, J. (2002). La familia en la pantalla: Percepción social y representación audiovisual de etnomodelos procreativos en el cine y la televisión en España. Oviedo: Septem Ediciones.

ImBert, G. (1982). Elena Francis, un consultorio para la transición: Contribución al estudio de los simulacros de masas. Barcelona: Península.

- (1990). Los discursos del cambio: Imágenes e imaginarios sociales en la España de la Transición (1976-1982). Madrid: Akal/Comunicación.

IPAR, J.J. El banquete según Freud. [http://www.marietan.com/otros\%20autores/El\% 20banquete\%20segun\%20freud_Ipar.htm, consulta: febrero de 2006]

Lipovetsky, G. (1990). El imperio de lo efimero. Barcelona: Anagrama.

LOMAS, C. (comp.) (2003). ¿Todos los hombres son iguales?: Identidades masculinas y cambios sociales. Barcelona: Paidós.

LozANO, J. (2000). «Simmel: la moda, el atractivo formal del límite». Revista Española de Investigaciones Sociológicas, 89, 237-250.

LuCERGa PÉREZ, M.J. Ciborgs, forenses y la axila de Sanex: El cuerpo en la sociedad mediática. [http://www.um.es/tonosdigital/znum7/estudios/icuerpodef.htm, consulta: marzo de 2009]

MÉRIDA, R. (ed.) (2002). Sexualidades transgresoras: Una antología de estudios queer. Barcelona: Icaria.

MuÑOZ, B. (coord.) (2001). Medios de comunicación, mujeres y cambio cultural. Madrid: Dirección General de la Mujer de la Comunidad de Madrid. 
SAmpedro, V. (ed.) (2003). La pantalla de las identidades: Medios de comunicación, politicas y mercados de identidad. Barcelona: Icaria.

SEIDLER, V.J. (2000). La sinrazón masculina: Masculinidad y teoría social. México: Paidós.

Thompson, J.B. (1998). Los media y la modernidad: Una teoría de los medios de comunicación. Barcelona: Paidós.

VendRell, J. (2002). «La masculinidad en cuestión: Reflexiones desde la Antropología». Revista de Ciencias Sociales, 61, 31-52.

Vilches, L. (1993). La televisión: Los efectos del bien y del mal. Barcelona: Paidós. ViÑuAles, O. (2000). Identidades lésbicas. Barcelona: Bellaterra. 